\title{
The influence of the body weight index (BMI) in the recovery of the degenerative diseases of the joints
}

\author{
Sînziana Călina Silişteanu *, Elisabeta Antonescu** \\ *Railway Clinical Hospital Iaşi - ,Ştefan cel Mare” University of Suceava, \\ Department of Health and Human Development \\ **University ,Lucian Blaga "Sibiu Faculty of Medicine \\ 1. Department of Medical Devices, Faculty of Pharmacy, Iuliu Hatieganu" University of \\ Medicine and Pharmacy Cluj-Napoca, Romania
}

\begin{abstract}
Objective: The trial proposes the evaluation of an efficient kinetic programme supported by hygiene and diet for the patients with degenerative diseases at the level of the joints.

Material and method: The trial was carried out under ambulatory conditions for a period of six months and it included two lots of patients diagnosed with degenerative diseases at the level of the hips and of the knees. They used a complex physical kinetic therapeutic treatment supported by a diet. The lots were evaluated according to the pain scale VAS, to the scale WOMAC, to the quality of life index QOL and to the body weight index BMI. The family's involvement was also monitored during the patients' recovery period.

The results pointed out that the patients who had followed a complex physical kinetic therapeutic treatment and a diet had significantly better results in comparison to the ones who did not follow the indications of the diet. It was noticed that some patients abandoned the physical exercises, predominantly the women.

Conclusions: The complex recovery treatment depends on a complex team: the physician, the physio-kinetic therapist, the nutritionist, the dietetician and the psychologist. The profilaxy of these diseases is very important and the treatment has to be individualised. It was noticed that the motivation and the education were defining elements for the recovery. It is also worth mentioning the involvement of the family/friends in the period of recovery treatment.
\end{abstract}




\section{INTRODUCTION}

The degenerative diseases of the joints represent the most frequent joint suffering. For the persons who are over 50 years old, it is the second cause of impairment after the cardiovascular diseases, being considered a public health issue.

The arthrosis is especially located at the level of the joints with great mobility among which the hip and the knee. Some of the factors that determine the predisposition to the disease are the age, the gender, the heredity, the obesity and other comorbidities. An important role in triggering the disease is represented by the mechanic stress, the over-requirement, the traumatisms as well as other secondary alterations of the cartilage. The association between arthrosis and obesity seems to be more obvious especially for the women involving the knee whereas the obesity is considered a factor of systemic risk.

Material and method: The trial involved a number of 129 patients diagnosed with arthrosis at the knee level (gonarthrosis) and at the hip level (coxarthrosis). The evaluation of the patients was made at the beginning and at the end of the treatment as well as at the check-up two months later. A rigourous anamnesis and a complete clinical examination were made. The observed parameters were the age, the gender, the living environment, the life quality, the somato-metric indexes (the weight in $\mathrm{kg}$, the height in $\mathrm{m}$, the circumferences and the folds), the body weight index $\left(\mathrm{kg} / \mathrm{m}^{2}\right)$ and the disability.

Inclusion criteria: the pain in the knee/hip, the redness of the joints, the mobility reduction, the functional impotence of different degrees, the age over 30, the possibility to evaluate the patient during the trial.

Exclusion criteria: the age over 30, the traumatic diseases, the aseptic necrosis, the reactive arthritis, the psychical diseases and the tumoral diseases.
The data were collected according to the medical ethics principles.

The recovery included hygiene and a diet, medication (anti-inflammatory, nonsteroidian, anti-pain), the physical treatment (low frequency currents, of average frequency, diathermy, laser and ultrasound), kinetic therapy.

The evaluation of the lots was made by using the pain scale VAS, the scale WOMAC, the quality of life index scale QOL, the body weight index IMC.

The visual analogous scale (VAS) is used for the determination of the pain intensity, whereas the patient is instructed to indicate the level of the painful sensation, which is used as a numerical index of the pain severity. This scale measures the sensorial intensity of the pain and allows the comparison of the values; it is a simple non-invasive method, very easy to be used by the patient.

The quality of life index was evaluated by using Quality of Life Scale QOL, which includes 16 items used in order to appreciate the patient's clinical and functional status. The scale appreciates the physical and social activity, the functional capacity, the independence in activities, the patient's physical condition, the satisfaction and the appreciation of the health condition after a treatment. The values for each question range from 1 to 7 whereas the limits for this scale range from $16 p$ (totally dissatisfied) to $112 p$ (very satisfied).

The Scale WOMAC (Western Ontario and McMaster Universities) includes 24 items and it is used in order to evaluate the status of the patients with hip or knee arthrosis; the minimal score is 0 and the maximal score is 96.

The body weight index BMI is an important indicator for the estimation of the nutrition state. It was calculated by using the Quetelet formula [IMC $=$ Weight $(\mathrm{Kg}) /$ Height $^{2}$ (m)]. A value of the body weight index between 20 and $24.9 \mathrm{~kg} / \mathrm{m}^{2}$ is considered normal (World Health Organisation WHO), between 25 and $29.9 \mathrm{~kg} / \mathrm{m}^{2}$ is considered as an index for the overweight persons, and over $30 \mathrm{~kg} / \mathrm{m}^{2}$ is considered as a diagnosis for obesity. The 
obesity was classified in degree 1 IMC between 30 and $34.9 \mathrm{~kg} / \mathrm{m}^{2}$, degree 2 IMC between 35 and $39.9 \mathrm{~kg} / \mathrm{m}^{2}$ and degree 3 or morbid obesity IMC over $40 \mathrm{~kg} / \mathrm{m}^{2}$ (WHO 1995).

It was important for the clinical evaluation to take into consideration both subjective and objective appreciations related to the joints, namely: pain, volume modifications, local temperature, movement directions and movement amplitude +/- normal articulary movements.

Therapy methods with physical factors:

The applications with US were used due to the anti-pain, anti-inflammatory and fibrolitic effects. The ultrasound therapy is useful in acute, sub-acute and chronic stages. The areas exposed to the ultrasound action recorded a selective heating accompanied by the increase of the threshold to pain and the moderate increase of the blood flow. The used form is the pulsatory one which reduces the profound thermic effect in the continuous form, applications in the mobile field. The parameters for the ultrasound: the work frequency of 1 $\mathrm{MHz}$, with intensity of $0.8 \mathrm{~W} / \mathrm{cm}^{2}$ which can provide a penetration of 3-6 cm, length of 4 minutes in the daily application.

The interferential currents were applied for the anti-pain, decontracting, tonic and trophic effects upon the profound tissues. The applications were bipolar and tetrapolar, with the modulation of $90-100 \mathrm{~Hz}$ for predominantly analgesic action, for 10 minutes in the daily application.

The laser applications were used for the anti-pain and anti-inflammatory effects. The used parameters were the frequency of $5-15 \mathrm{~Hz}$ and a density of 4-8 Jouli- $\mathrm{cm}^{2}$.

The low frequency currents: The use of Trabert current which has a fixed frequency of $140 \mathrm{~Hz}$, the length of the impulse $2 \mathrm{~ms}$ and of the pause $5 \mathrm{~ms}$, determins anti-pain, excitingmotor and hyperemiant effects. The analgesic effect may occur immediately at the end of the session, in approximately 10 minutes.
As for the diet, it was important to take into consideration elements of aging physiology, modifications of the body weight index and the decrease of the muscular mass which were correlated with the decrease of the food intake from the viewpoint of the quantity and and of the quality and the vitamin deficit [1]. There was an attempt at educating patients about the nutrition state and at requesting the family's help. It is known that the basic metabolism decreases with approximately 100 kcalories a day per age decade; that is why it was taken into account during the reduction of the calory number (lower than 1,500 kcalories a day) that the diet should contain a lot of fibre, carbohydrates, fruit, vegetables, with the substantial reduction of the animal fat quantity [2]. The persons who were over 65 , especially the ones who had other diseases (cardiovascular, digestive, obesity), by inactivity, were found to have modifications of the body weight index, the decrease of the muscular mass, sometimes accompanied by the decrease of the quantity and quality food intake, vitamin deficit [3].

The nutrition is an important determining factor especially for the persons over 65 . The nutrition state may be involved in triggering some cardiovascular diseases, cancer and the aggravation of the rheumatological ones.

The kinetic therapy was performed individually and in a group, rhythmically, with average intensity adapted to the age group.

The pursued objectives for gonarthrosis were: the remake of the joint mobility (earning the extension-positioning, stretching for the quadriceps muscle and for ischium-shanks), the remake of the muscular tonus (it was aimed at remaking the extensor force for the last $20^{\circ}$ isotonic contractions in an open and closed chain, and with precautions, isometric contractions), the remake of the equilibrium and of the stability. Passive or active or resistance active mobilizations were carried out according to the stage of the disease and to the presence of other diseases.

The objectives for coxarthrosis were: the reduction of pain, the increase of the joint mobility, the increase of the stability, the increase of the coordination degree and the 
regain of the walking equilibrium. The patients used correcting positioning, proprioceptive neuro-muscular facilitation techniques (rhythmic stabilization, hold-relax, isometric and isotonic contraction alternation), passive and active mobilizations, therapy by pulleys, tractions in the ax (decontracting anti-pain role), muscular tonifiation techniques by exercises in closed kinetic chain, muscular tonifiation (big buttocks, average buttocks, ischium-shanks, quadriceps), exercises on the ergonomic bicycle.

All the kinetic recovery programmes were carried out by taking into account the patients' health condition, work parameters and their individual possibilities.

The patients were distributed into two lots: the trial lot L1 was made up by 67 patients whereas the witness lot was made up of 62 patients. The lotul L1 had more girls and women $(52.23 \%)$ whereas the lot L2 had more boys and men $(51.61 \%)$. Most of the patients in the lot L1, namely $53.73 \%$ came from the rural environment whereas most of the patients in the lot L2, namely $54.84 \%$ came from the urban environment

Table 1: The distribution of the patients in the lots L1 and L2 according to gender and age groups (30-44 years old, 45-59 years old, 60-75 years old, over 75 years old)

\begin{tabular}{|c|c|c|c|c|c|}
\hline LOT & SEX & 30-44 years old & 45-59 years old & 60-75 years old & over 75 years old \\
\hline \multirow[t]{2}{*}{ LOT 1} & FEMALE & 6 & 12 & 10 & 7 \\
\hline & MALE & 6 & 11 & 10 & 5 \\
\hline \multirow[t]{2}{*}{ LOT 2} & FEMALE & 6 & 10 & 8 & 6 \\
\hline & MALE & 5 & 10 & 10 & 7 \\
\hline
\end{tabular}

Figure 1: The distribution of the patients in the lots L1, L2 according to gender and age groups

Table 2: The distribution of the patients in the lots L1 and L2 according to the living environment and age groups

\begin{tabular}{|c|c|c|c|c|c|}
\hline LOT & MEDIU & 30-44 years old & 45-59 years old & 60-75 years old & over 75 years old \\
\hline \multirow[t]{2}{*}{ LOT 1} & URBAN & 8 & 11 & 11 & 6 \\
\hline & RURAL & 4 & 12 & 9 & 6 \\
\hline \multirow[t]{2}{*}{ LOT 2} & URBAN & 6 & 12 & 9 & 7 \\
\hline & RURAL & 5 & 8 & 9 & 6 \\
\hline
\end{tabular}

Figure 2: The distribution of the patients in the lots L1 and L2 according to the living environment and age group 
The distribution on age groups shows that most of the patients in the lot L1 were in the age groups $45-59$ years (23 patients) and $60-75$ years (20 patients). A similar situation may be encountered in the lot L2, namely for the age group 45-59 years old with 20 patients and for the age group 60-75 years with 18 patients.

\section{RESULTS}

At the beginning of the treatment, after calculating the body weight index BMI, out of 67 patients in the lot L1, 20.9\% had a normal weight, $37.31 \%$ were overweight, $23.88 \%$ had obesity $1^{\text {st }}$ degree, $11.94 \%$ obesity $2^{\text {nd }}$ degree, $5.97 \%$ obesity $3^{\text {rd }}$ degree.

It was found out during the final evaluation that the patients lost weight; after the body weight index had been calculated, $32.84 \%$ had normal weight, $43.28 \%$ were overweight, $14.92 \%$ had obesity $1^{\text {st }}$ degree, $2.98 \%$ had obesity $2^{\text {nd }}$ degree and $5.97 \%$ had obesity $3^{\text {rd }}$ degree.

The results of the check-up indicated the increase in the number of patients with normal weight and the decrease of the ones with overweight and obesity. Thus, $59.7 \%$ had normal weight, $25.37 \%$ were overweight, $10.45 \%$ had obesity $1^{\text {st }}$ degree, $4.48 \%$ had obesity $2^{\text {nd }}$ degree and $1.49 \%$ had obesity $3^{\text {rd }}$ degree.

Table 3: The distribution of the patients in the lots L1 and L2 according to BMI.

\begin{tabular}{|c|c|c|c|c|c|c|}
\hline Lot & Moment & Normal weight & Overweight & Obesity- $\mathbf{1}^{\text {st }}$ degree & Obesity- $\mathbf{2}^{\text {nd }}$ degree & Obesity- $\mathbf{3}^{\text {rd }}$ degree \\
\hline & & $(\%)$ & $(\%)$ & $(\%)$ & $(\%)$ & $(\%)$ \\
\hline L1 & Initial & $\mathbf{2 0 , 9}$ & $\mathbf{3 7 , 3 1}$ & $\mathbf{2 3 , 8 8}$ & $\mathbf{1 1 , 9 4}$ & $\mathbf{5 , 9 7}$ \\
\hline & Final & $\mathbf{3 2 , 8 4}$ & $\mathbf{4 3 , 2 8}$ & $\mathbf{1 4 , 9 2}$ & $\mathbf{2 , 9 8}$ & $\mathbf{5 , 9 7}$ \\
\hline & Control & $\mathbf{5 9 , 7}$ & $\mathbf{2 5 , 3 7}$ & $\mathbf{1 0 , 4 5}$ & $\mathbf{4 , 4 8}$ & $\mathbf{4 9}$ \\
\hline $\mathbf{L}$ & Initial & $\mathbf{1 9 , 3 5}$ & $\mathbf{4 0 , 3 2}$ & $\mathbf{2 7 , 4 2}$ & $\mathbf{8 , 0 6}$ & $\mathbf{4 , 8 4}$ \\
\hline & Final & $\mathbf{2 0 , 9 7}$ & $\mathbf{4 6 , 7 6}$ & $\mathbf{1 9 , 3 5}$ & $\mathbf{8 , 0 6}$ & $\mathbf{4 , 8 4}$ \\
\hline & Control & $\mathbf{2 4 , 1 9}$ & $\mathbf{5 1 , 6 1}$ & $\mathbf{1 6 , 1 3}$ & $\mathbf{3 , 2 2}$ & $\mathbf{4 , 8 4}$ \\
\hline
\end{tabular}

At the beginning of the treatment, after calculating the body weight index BMI, out of 62 patients in the lot L2, $19.35 \%$ had normal weight, $40.32 \%$ were overweight, $27.42 \%$ had obesity $1^{\text {st }}$ degree, $8.06 \%$ obesity $2^{\text {nd }}$ degree, $4.84 \%$ obesity $3^{\text {rd }}$ degree.

At the final evaluation, after calculating the body weight index BMI, 20.97\% had normal weight, 46.77 were overweight, $19.35 \%$ had obesity $1^{\text {st }}$ degree, $8.06 \%$ obesity $2^{\text {nd }}$ degree and $4.84 \%$ obesity $3^{\text {rd }}$ degree.

The results during the control indicated the increase in the number of the patients with normal weight and the decrease of the overweight persons and of the obese ones. Thus, $24.19 \%$ had normal weight, $51.61 \%$ were overweight, $16.13 \%$ had obesity $1^{\text {st }}$ degree, $3.22 \%$ had obesity $2^{\text {nd }}$ degree and $4.84 \%$ had obesity $3^{\text {rd }}$ degree.

Figure 3: The distribution of the patients in the lots L1 and L2 according to the body weight index BMI
A nutritional education programme is closely related to the individualized physical activity. The favouring factors involved in the weight increase and implicitly in the modification of the body weight index BMI are: the disordered feeding, the depression, the physical and psychical the over-requirement and the incorrectly applied diets.

The individual patients were recommended a diet without any excess of sugar, salt, fat reduced as a number of calories, being indicated examples of daily menus in the recovery period.

The statistically significant values are pointed out for BMI, VAS and QOL in the lot L1 in comparison to the lot L2 for the initial evaluation, for the final one and for the checkup. For the evaluation by WOMAC scale, the results are statistically insignificant for both lots. 


\begin{tabular}{|l|l|c|c|c|c|c|c|}
\hline Lot & Statistic functions & \multicolumn{3}{|c|}{ BMI } & \multicolumn{3}{c|}{ VAS } \\
\hline \multirow{2}{*}{ L1 } & \multicolumn{1}{|c|}{ I } & F & C & I & F & C \\
\cline { 2 - 8 } & $\begin{array}{l}\text { Median and } \\
\text { standard deviation }\end{array}$ & $29.06 \pm 5.60$ & $26.34 \pm 5.71$ & $23.67 \pm 5.72$ & $7.0 \pm 0.70$ & $4.0 \pm 0.46$ & $2.0 \pm 0.50$ \\
\cline { 2 - 8 } & T-student test & $\mathbf{0 . 0 0 1 9 0}$ & $\mathbf{9 . 3 2 E - 0 5}$ & $\mathbf{0 . 0 0 2 3 7 9 1 2}$ & $\mathbf{0 . 0 4 1 1 9 4}$ & $\mathbf{0 . 0 3 0 2 0 4}$ & $\mathbf{0 . 0 6 4 1 8 8}$ \\
\hline \multirow{2}{*}{ L2 } & $\begin{array}{l}\text { Median and } \\
\text { standard deviation }\end{array}$ & $29 . \pm 5.03$ & $28.5 \pm 5.01$ & $\mathbf{2 7 . 5} \pm 4.87$ & $7.0 \pm 1.44$ & $\mathbf{5 . 5} \pm 1.52$ & $3.0 \pm 1.24$ \\
\cline { 2 - 8 } & T-student test & $\mathbf{5 . 5 6 E - 0 5}$ & $\mathbf{3 . 9 E}-07$ & $\mathbf{0 . 0 0 0 2 2}$ & $\mathbf{0 . 0 1 1 9 7 3}$ & $\mathbf{0 . 0 1 6 1 9 5}$ & $\mathbf{0 . 0 7 5 2 5 4}$ \\
\hline
\end{tabular}

\begin{tabular}{|c|l|c|c|c|c|c|c|}
\hline \multirow{2}{*}{ Lot } & Statistic functions & \multicolumn{3}{|c|}{ QOL } & \multicolumn{3}{c}{ WOMAC } \\
\hline \multirow{2}{*}{ L1 } & & I & F & C & I & F & C \\
\cline { 2 - 7 } & $\begin{array}{l}\text { Median and } \\
\text { standard deviation }\end{array}$ & $\mathbf{0 . 7 5} \pm 0.01$ & $\mathbf{0 . 8 1} \pm 0.09$ & $\mathbf{0 . 9 8} \pm 0.05$ & $7.0 \pm 4.19$ & $3.0 \pm 2.70$ & $1.0 \pm 1.43$ \\
\cline { 2 - 7 } & T-student test & $\mathbf{0 . 0 0 2 1 6 8}$ & $\mathbf{0 . 0 0 0 1 9 3}$ & $\mathbf{0 . 0 0 5 3 1 5}$ & $\mathbf{0 . 2 7 1 1 9 1}$ & $\mathbf{0 . 3 3 4 8 4}$ & $\mathbf{0 . 4 7 9 0}$ \\
\hline \multirow{2}{*}{ 2 } & $\begin{array}{l}\text { Median and } \\
\text { standard deviation }\end{array}$ & $\mathbf{0 . 7 5} \pm 0.09$ & $\mathbf{0 . 8 4} \pm 0.07$ & $\mathbf{0 . 9 8} \pm 0.06$ & $\mathbf{1 2 . 0} \pm 8.38$ & $\mathbf{7 . 0} \pm 6.27$ & $\mathbf{3 . 0} \pm 4.58$ \\
\cline { 2 - 7 } & T-student test & $\mathbf{0 . 0 0 2 3 9 2}$ & $\mathbf{0 . 0 0 2 3 9 2}$ & $\mathbf{0 . 0 0 3 1 2 7}$ & $\mathbf{0 . 2 5 3 7 4 3}$ & $\mathbf{0 . 3 8 0 4}$ & $\mathbf{0 . 4 3 1 2}$ \\
\hline
\end{tabular}

The values of the median and the standard deviation for the lots L1 and L2

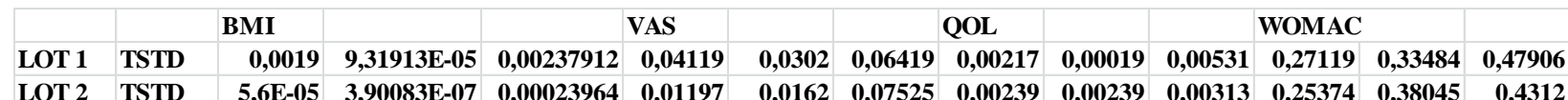
Values for the t-student test for the lots L1 and L2

The results pointed out that the patients who followed a complex physical kinetic therapeutic treatment and who complied with the hygiene and with the diet had superior results than the patients who did not take into account the physical exercise programme completed by the diet. Some patients abandoned the individualized programme of physical exercises.

\section{Conclusions}

The statistically significant values for the evaluation BMI, VAS and QOL allow us to assert that the nutritional status can influence the recovery period, its quality and the resumption of the daily activities by ther patients diagnosed with arthrosis at the knee and at the hip. [4]Another conclusion refers to the fact that statistically significant differences between the body weight indexes according too the age group, gender and the performed physical activity.

The complex recovery treatment depends on a complex team. The profilaxy of these diseases is very important whereas the treatment has to be individualized. The motivation and the education were remarked as defining elements for the recovery [5].

\section{Bibliografie}

[1] St.John B.Coombs, Albert Barrocas, Jane V. White "Nutrition Care of Older Adults with Chronic Diseases: Attitudes and Practices of Physicians and Patients", Southern Medical Journal 97(6):560-5 · July 2004

[2] Patterson R.E., Haines P.S., Popkin B.M. "Diet quality index: capturing a multidimensional behavior" J. Am. Diet Assoc. 1994 Jan; 94(1):57-64.

[3] M.H. Pope, T. Bevins, D.G. Wilder, J.W. Frymoyer, "The Relationship Between Anthropometric, Postural, Muscular and Mobility Characteristics of Males Aged 18-55," Spine, 2015.

[4] S.C. Silişteanu and M. Covaşă "Reduction of Body Weight through Nutrition Intervention Reduces Chronic Low Back Pain"- The $5^{\text {th }}$ IEEE International Conference on E-Health and Bioengineering - EHB 2015

[5] S.M. Cambi "The effect of low-fat diet and exercise on C-reactive protein and metabolic 